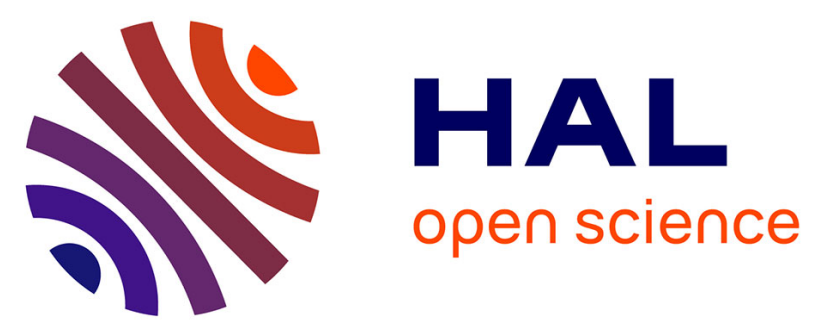

\title{
Design, synthesis, antimicrobial evaluation, and molecular docking studies of novel symmetrical 2,5-difunctionalized 1,3,4-oxadiazoles
}

Shaima Hkiri, Afifa Hafidh, Jean-François Cavalier, Soufiane Touil, Ali Samarat

\section{To cite this version:}

Shaima Hkiri, Afifa Hafidh, Jean-François Cavalier, Soufiane Touil, Ali Samarat. Design, synthesis, antimicrobial evaluation, and molecular docking studies of novel symmetrical 2,5-difunctionalized 1,3,4-oxadiazoles. Journal of Heterocyclic Chemistry, 2019, 10.1002/jhet.3837 . hal-02401543

\section{HAL Id: hal-02401543 \\ https://hal-amu.archives-ouvertes.fr/hal-02401543}

Submitted on 30 Jan 2020

HAL is a multi-disciplinary open access archive for the deposit and dissemination of scientific research documents, whether they are published or not. The documents may come from teaching and research institutions in France or abroad, or from public or private research centers.
L'archive ouverte pluridisciplinaire HAL, est destinée au dépôt et à la diffusion de documents scientifiques de niveau recherche, publiés ou non, émanant des établissements d'enseignement et de recherche français ou étrangers, des laboratoires publics ou privés. 


\title{
Design, synthesis, antimicrobial evaluation and molecular docking studies of novel symmetrical 2,5-difunctionalized 1,3,4-oxadiazoles
}

\author{
Shaima Hkiri ${ }^{\mathrm{a}}$, Afifa Hafidh ${ }^{\mathrm{b}}$, Jean-François Cavalier ${ }^{\mathrm{c}}$, Soufiane Touil ${ }^{\mathrm{a}}$, Ali Samarat ${ }^{\mathrm{a}^{*}}$ \\ ${ }^{a}$ University of Carthage, Faculty of Sciences of Bizerte, LRI8ES11 Laboratory of Hetero-Organic Compounds and \\ Nanostructured Materials, 7021 Zarzouna, Tunisia. \\ ${ }^{b}$ University of Tunis, Preparatory Institute for Engineering Studies of Tunis, UR99/12-16 Materials and Environment Unit, 1008, \\ Tunis, Tunisia. \\ ${ }^{c}$ Aix-Marseille University, CNRS, LISM, IMM FR3479, Marseille, France.
}

E-mail : ali.samarat@gmail.com

\section{Acknowledgements}

We thank the Tunisian Ministry of Higher Education and Scientific Research for financial support (LR18ES11). We would also like to thank Professor Mosadok Ben Attia (University of Carthage, Faculty of Sciences of Bizerte) for his fructuous discussion about antimicrobial activity of our products.

\begin{abstract}
A series of novel symmetrical 2,5-difunctionalized 1,3,4-oxadiazole derivatives of pharmacological significance have been synthesized. The obtained compounds were screened for their in vitro antimicrobial activities against Gram-negative (Escherichia coli and Salmonella typhimurium) and Gram-positive bacteria (Staphylococcus aureus, Enterococcus feacium and Streptococcus agalactiae or group B Streptococcus), as well as against the fungus Candida albicans. Although the synthesized compounds showed moderate antifungal activity against $C$. albicans, they exhibited good to excellent antibacterial activities against several strains, compared with standard drugs Ampicillin and Nystatin. In silico molecular docking in FabI enzyme active site, gave information regarding the binding mode of the drug candidate at molecular level.
\end{abstract}

Keywords: 1,3,4-oxadiazole; amidines; symmetrical 2,5-difunctionalized 1,3,4-oxadiazoles; antibacterial activity; antifungal activity; molecular docking. 


\section{INTRODUCTION}

For the past few years, there has been a growing interest in developing new antimicrobial agents from various sources to combat microbial resistance [1]. Currently, treatment failures associated with multidrug-resistant bacteria have become a critical problem worldwide and one of the most important current threats to public health [2,3]. As a consequence, the discovery of new antimicrobial agents is an exclusively important objective. Nowadays, synthetic products still remain one of the major sources of new drug molecules. Sulfonamides, oxazolidinones and fluoroquinolones [4] are indeed the most frequently-used antimicrobial drugs from synthetic origin.

1,3,4-Oxadiazoles are valuable five-membered aromatic heterocycles that possess a wide range of biological properties, including antibacterial [5-9], antifungal [10-12], antiviral [13,14], antiinflammatory [15], antiparasitic [15], and anti-HIV [17,18] activities. Some examples of drugs used in clinical medicine, containing the 1,3,4-oxadiazole unit, are furamizole which is an antibiotic drug, and raltegravir, an antiretroviral medication used to treat HIV infection [19] (Fig. 1). On the other hand, the amide, amidine, imine and aminoguanidine functional groups are important antimicrobial pharmacophores, and the introduction of such functionalities to the 1,3,4-oxadiazole core could improve the antimicrobial activity of such compounds, in conformity with the active substructure combination principle. Indeed, some commercialized antimicrobial drugs, such as linezolid and pentamidine (Fig. 1), contain in their structures the amide and amidine moieties, respectively [20,21]. Furthermore, it was found that introducing an imine or aminoguanidine group into sulfonamides could significantly improve the antimicrobial activity of the target compounds by 4 to 16-fold [22,23] (Fig. 1).

In view of the above, and as a continuation of our interest to develop efficient protocols for the synthesis of heterocyclic compounds with possible biological properties [24], we now report a convenient one-step synthesis of 1,3,4-oxadiazole-2,5-diamine, through the hydrogen peroxide-promoted oxidative dimerization of urea, followed by intramolecular cyclisation. A wide variety of unprecedented symmetrical 2,5-difunctionalized 1,3,4-oxadiazoles bearing the amide, amidine, imine, or aminoguanidine functional groups, was then easily obtained from the reaction of 1,3,4-oxadiazole-2,5-diamine with different carbonyl or thiocarbonyl electrophiles such as salicylic acid, paracetamol, phenacetin, $\alpha$-tetralone, sorbic acid and thiosemicarbazide. All the synthesized compounds were screened for their antimicrobial activity and they showed moderate to high antibacterial and antifungal efficacy against several microbial strains. 


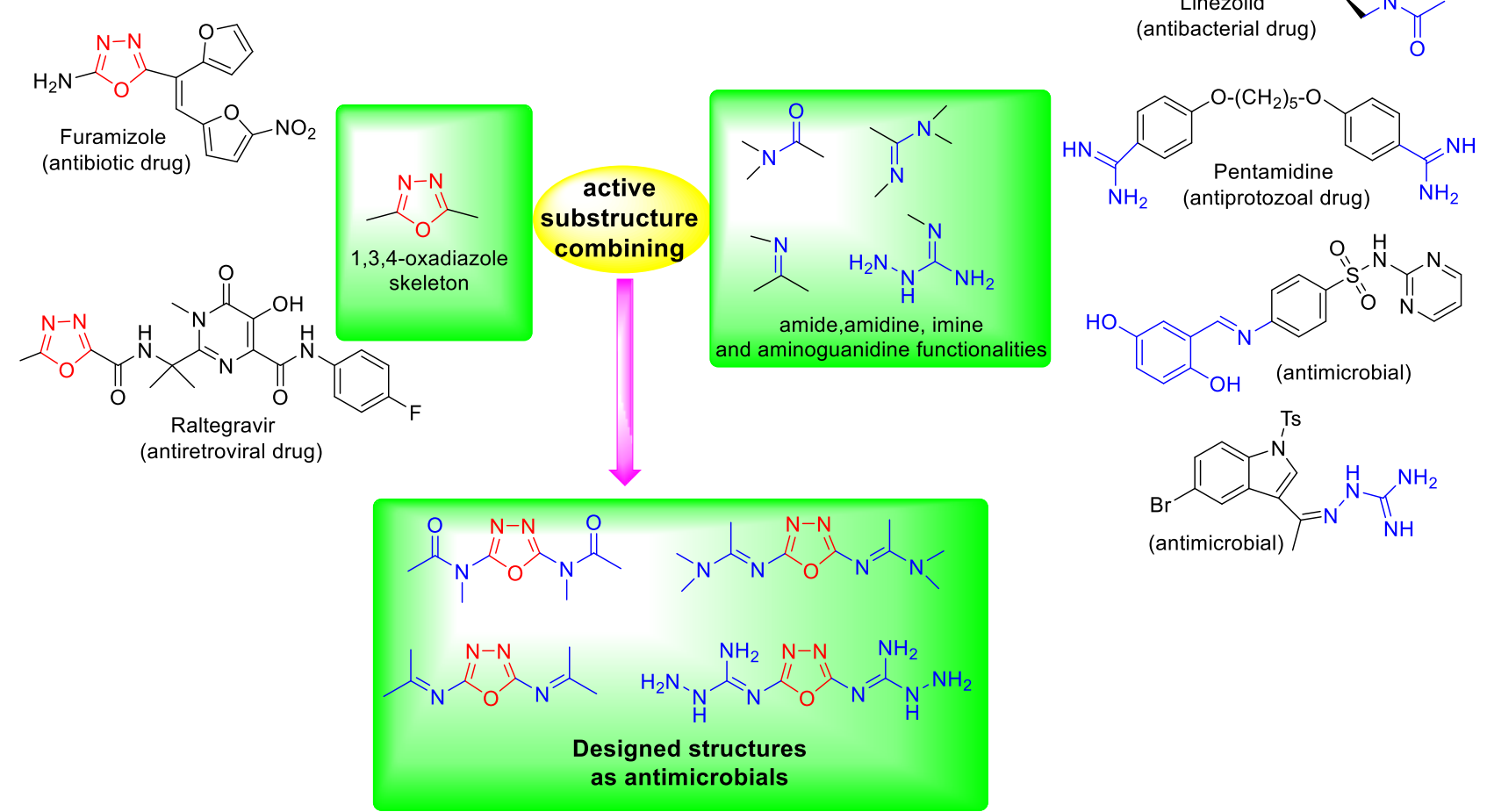

Fig. 1. Design strategy of target structures.

\section{RESULTS AND DISCUSSION}

Synthesis. In the first part of this work, we focused our efforts to synthesize the 1,3,4-oxadiazole2,5-diamine 1 (Scheme 1). Being a binucleophilic agent with two amino groups in symmetrical 2,5positions, this compound could undergo condensation reactions with carbonyl or thiocarbonyl electrophiles leading to the target structures.

A literature survey on the preparation of 1,3,4-oxadiazole-2,5-diamine 1 showed only a few specific synthetic routes, most of these involving dehydrative cyclisation of the hardly accessible hydrazine-1,2-dicarboxamide [25,26]. Therefore, a step-economic and low-cost approach to synthesize this heterocyclic scaffold from easily obtained starting materials is of great significance. With this in mind, we developed a convenient one-step synthesis of 1,3,4-oxadiazole-2,5-diamine 1, through the hydrogen peroxide-promoted oxidative dimerization of urea, followed by intramolecular cyclisation. The reaction was achieved in a simple one-step protocol, by treating urea with excess $\mathrm{H}_{2} \mathrm{O}_{2}$ in the presence of a catalytic amount of sulfuric acid and heating the mixture under reflux for $24 \mathrm{~h}$ (Scheme 1). The desired 1,3,4-oxadiazole-2,5-diamine 1 was obtained as a white solid in 72\% yield, after recrystallization from ethanol. By comparison with existing methods [25,26], our protocol, 
which uses commercially available and low-cost urea, hydrogen peroxide and sulfuric acid as starting materials, is endowed with several other advantages such as easy operation, satisfactory yield and mild reaction conditions.

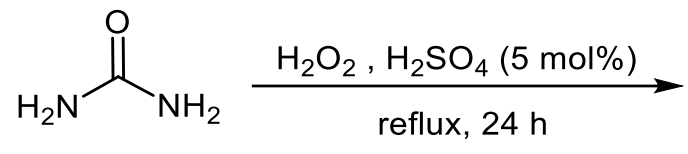<smiles>Nc1nnc(N)o1</smiles>

Scheme 1. One-step synthesis of 1,3,4-oxadizole-2,5-diamine 1.

A plausible mechanism for the formation of compound $\mathbf{1}$ is depicted in Scheme 2. The reaction is assumed to proceed, firstly, via oxidative dimerization of urea promoted by hydrogen peroxide in the presence of sulfuric acid as catalyst. This will afford the crucial intermediate hydrazine-1,2dicarboxamide, which then undergoes an acid-catalyzed intramolecular cyclisation through its reactive tautomer form. A subsequent dehydrative aromatization leads to the target compound 1,3,4-oxadiazole-2,5-diamine 1 (Scheme 2).

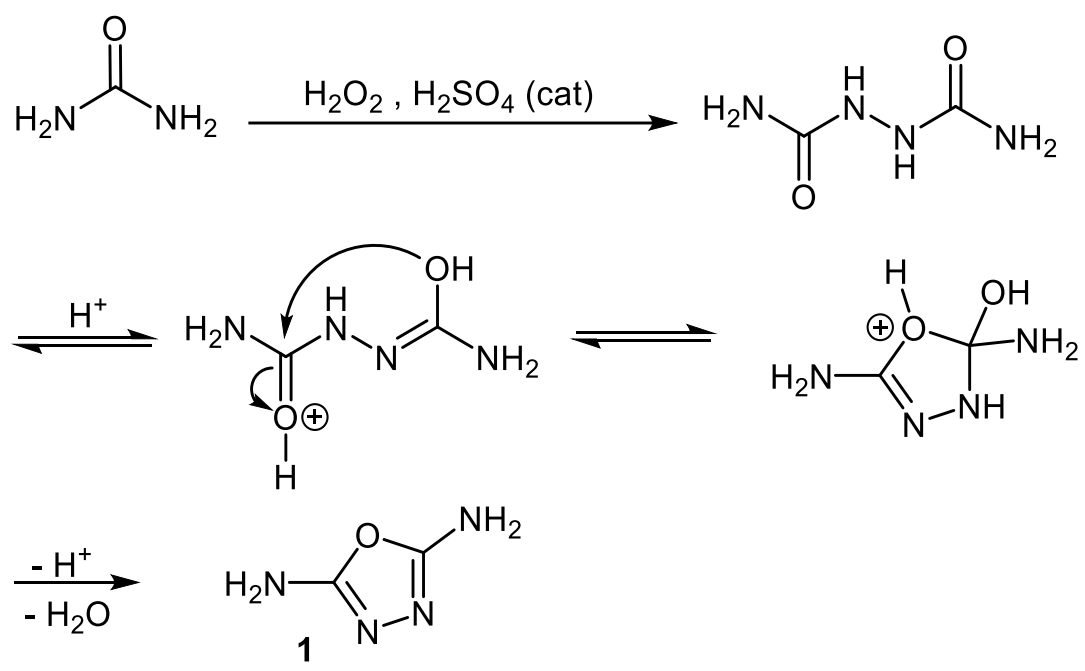

Scheme 2. Proposed mechanism for the formation of 1,3,4-oxadizole-2,5-diamine $\mathbf{1 .}$

With the 1,3,4-oxadiazole-2,5-diamine $\mathbf{1}$ in hand, we next studied its reaction with various commercially available carbonyl or thiocarbonyl electrophiles such as salicylic acid, paracetamol, phenacetin, $\alpha$-tetralone, sorbic acid and thiosemicarbazide, which would allow a straightforward approach to the target symmetrical 2,5-difunctionalized 1,3,4-oxadiazoles incorporating the amide, amidine, imine, or aminoguanidine functional groups. The reactions were found to proceed efficiently by condensing compound $\mathbf{1}$ with two molar equivalents of the above-mentioned carbonyl or thiocarbonyl electrophile, in refluxing ethanol for 4-12 h, in the presence of a catalytic amount of 
sulfuric acid (Scheme 3). The desired 2,5-difunctionalized 1,3,4-oxadiazoles 2-7 were then obtained as solids in $75-86 \%$ yield, after recrystallization from ethanol.

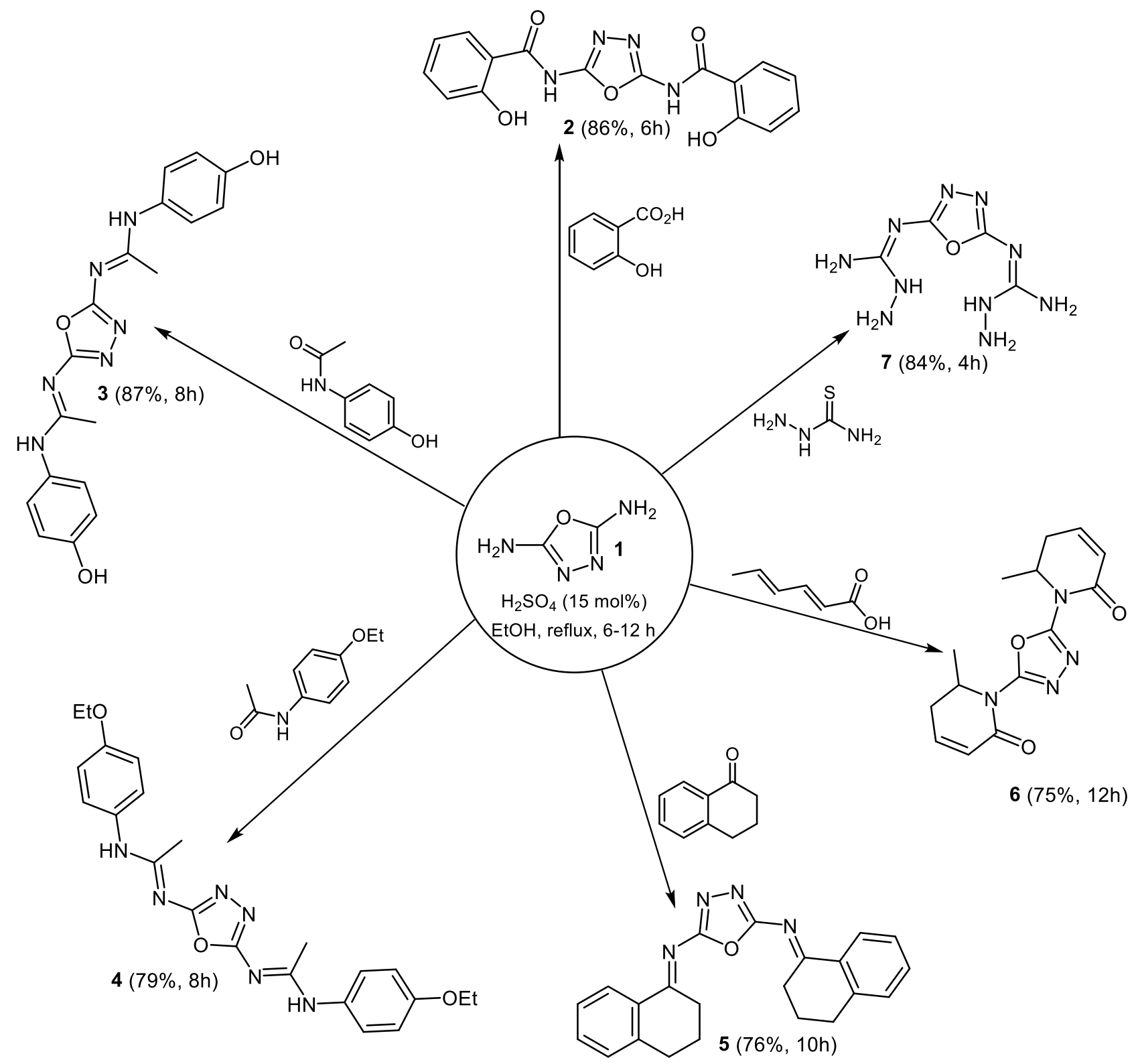

Scheme 3. Synthesis of symmetrical 2,5-difunctionalized 1,3,4-oxadiazoles 2-7.

It should be mentioned that in case of sorbic acid used as carbonyl electrophile (Scheme 3, product 6), an atypical reaction behaviour was observed. As shown in Scheme 4, the condensation proceeds firstly via a nucleophilic conjugate addition leading to the $\delta$-amino-acid intermediate, which then undergoes an intramolecular cyclisation through a 6-exo-trig process [27], followed by spontaneous dehydration, to afford the corresponding 1,3,4-oxadiazole $\mathbf{6}$, bearing two dihydropyridinone moieties in symmetrical 2,5-positions. 

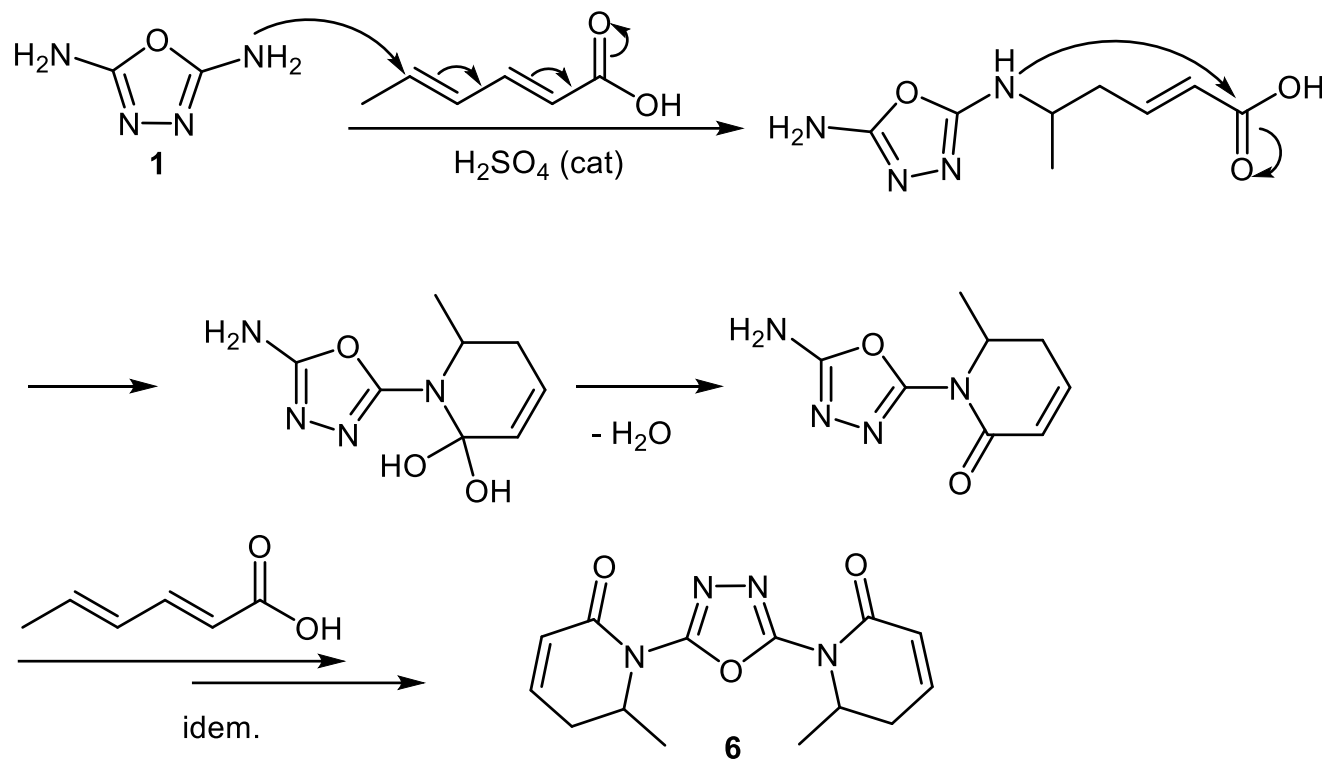

Scheme 4. A mechanistic rationalization for the formation of compound 6.

Antimicrobial activity. The newly synthesized compounds 2-7 as well as the starting 1,3,4oxadiazole-1,5-diamine 1, were investigated for their in vitro antimicrobial activities against Gram negative (Escherichia coli and Salmonella typhimurium) and Gram positive bacteria (Staphylococcus aureus, Enterococcus feacium and Streptococcus agalactiae or group B Streptococcus), as well as against the fungus Candida albicans. Their antimicrobial properties were first assessed by the inhibition zone diameter using filter paper disc-diffusion method [28]. Then, their respective minimum inhibitory concentration (MIC) and minimum bactericidal concentration (MBC) (i.e., the minimum fungicidal concentration MFC for C. albicans), were determined using the MTT assay [29] and the agar plating method [28], respectively. The results were compared to the commercially available Ampicillin [30] used as positive control for bacterial strains, and Nystatin [31] used as positive control for clinical strains of Candida albicans.

As indicated in Table 1, at the concentration of $15 \mu \mathrm{g} / \mathrm{mL}$, the majority of tested compounds displayed good to excellent inhibitory effects against all bacterial strains with a variable inhibition zone diameter ranging from 7 to $46.5 \mathrm{~mm}$. In contrast, their antifungal activity was found to be moderate against the clinical Candiat albicans, compared to standard Nystatin. Furthermore, for all examined bacterial and fungal strains, the newly synthesized 2,5-difuctionnalized 1,3,4-oxadiazoles 2-7 were found 1.1 to 5.5 fold more active than their precursor 1,3,4-oxadiazole-2,5-diamine 1 which showed the less diameter of the inhibition zone in all cases. 
Table 1. The in vitro antimicrobial activity of compounds 1-7 and the control drugs.

\begin{tabular}{ccccccc}
\hline \multirow{2}{*}{ Compound $^{\mathrm{a}}$} & \multicolumn{7}{c}{ Inhibition zone diameter $(\mathrm{mm})$} \\
\cline { 2 - 7 } & E. coli & S. typhimurium & S. aureus & E. feacium & S. agalactiae & C. albicans \\
\hline $\mathbf{1}$ & 7.00 & 7.50 & 7.00 & 9.00 & 8.50 & 8.00 \\
$\mathbf{2}$ & 9.25 & 9.50 & 15.25 & 25.50 & 37.75 & 9.25 \\
$\mathbf{4}$ & 13.75 & 12.00 & 18.25 & 27.00 & 36.50 & 11.00 \\
$\mathbf{5}$ & 12.75 & 11.50 & 16.00 & 25.50 & 46.50 & 11.25 \\
$\mathbf{6}$ & 12.25 & 12.25 & 14.25 & 17.75 & 29.25 & 10.00 \\
$\mathbf{7}$ & 10.00 & 9.50 & 13.25 & 15.00 & 15.50 & 10.50 \\
Ampicillin $^{\mathrm{a}}$ & 10.50 & 10.00 & 17.75 & 25.00 & 36.50 & 11.00 \\
Nystatin $^{\mathrm{b}}$ & 12 & 14.50 & 34.75 & 37.00 & 28.75 & - \\
\hline
\end{tabular}

${ }^{a}$ At the concentration of $15 \mu \mathrm{g} / \mathrm{mL},{ }^{b}$ At the concentration of $100 \mu \mathrm{g} / \mathrm{mL}$.

These results suggest that the incorporation of amide, amidine, imine or aminoguanidine functional groups into the 1,3,4-oxadiazole 2,5-diamine 1, allows to obtain more active compounds. Interestingly, 1,3,4-oxadiazoles derivatives $\mathbf{3}$ and $\mathbf{4}$ bearing two amidine moieties in symmetrical 2,5positions and resulting from the condensation of $\mathbf{1}$ with paracetamol and phenacetin, respectively, (Scheme 3, products 3 and 4), exhibited the best antibacterial activity against all microbial strains tested with inhibition zone ranging between 11.0 and $46.5 \mathrm{~mm}$ (Table 1). Moreover, except for compounds 6, all other tested 1,3,4-oxadiazole derivatives exhibited inhibitory effect against $S$. agalactiae strain, better than or comparable to that of Ampicillin used as positive control.

More accurate data on the antimicrobial activities of the synthesized compounds were obtained through their MIC (Table 2) and MBC (MFC for C. albicans) values (Table 3). For the sake of comparison, the MIC and MBC values of the positive references Ampicillin and Nystatin were also determined (Tables 2 and 3).

Table 2. Minimum inhibitory concentration (MIC) of compounds 1-7

\begin{tabular}{ccccccc}
\hline \multirow{2}{*}{ Compound } & \multicolumn{7}{c}{ MIC $\left(\mu \mathrm{g} . \mathrm{mL}^{-1}\right)$} \\
\cline { 2 - 7 } & E. coli & S. typhimurium & S. aureus & E. feacium & S. agalactiae & C. albicans \\
\hline $\mathbf{1}$ & 1.000 & 0.500 & 1.000 & 0.500 & 0.250 & 0.250 \\
$\mathbf{2}$ & 0.500 & 0.500 & 0.062 & 0.062 & 0.062 & 0.250 \\
$\mathbf{3}$ & 0.500 & 0.500 & 0.031 & 0.031 & 0.031 & 0.500 \\
$\mathbf{4}$ & 0.500 & 0.500 & 0.015 & 0.015 & 0.015 & 0.015 \\
$\mathbf{5}$ & 0.500 & 0.500 & 0.062 & 0.125 & 0.250 & 0.250 \\
$\mathbf{6}$ & 0.500 & 0.500 & 1.000 & 0.500 & 0.500 & 0.500 \\
$\mathbf{7}$ & 0.500 & 0.500 & 0.015 & 0.031 & 0.031 & 0.250 \\
Ampicillin & 0.031 & 0.015 & 0.004 & 0.004 & 0.003 & - \\
Nystatin & - & & - & - & - & 0.003 \\
\hline
\end{tabular}


Table 3. Minimum bactericidal concentration (MBC) of compounds 1-7

\begin{tabular}{|c|c|c|c|c|c|c|}
\hline \multirow{2}{*}{ Compound } & \multicolumn{6}{|c|}{$\mathrm{MBC}(\mu \mathrm{g} / \mathrm{mL})$} \\
\hline & E. coli & S. typhimurium & S. aureus & E. feacium & S. agalactiae & C. albicans $^{a}$ \\
\hline 1 & 1.000 & 1.000 & 1.500 & 1.000 & 0.500 & 0.500 \\
\hline 2 & 1.000 & 1.000 & 0.125 & 0.125 & 0.125 & 0.500 \\
\hline 3 & 1.000 & 1.000 & 0.062 & 0.062 & 0.062 & 1.000 \\
\hline 4 & 0.500 & 0.500 & 0.031 & 0.031 & 0.031 & 0.031 \\
\hline 5 & 1.000 & 1.000 & 0.125 & 0.250 & 0.125 & 1.000 \\
\hline 6 & 1.000 & 1.000 & 1.500 & 1.000 & 0.500 & 1.000 \\
\hline 7 & 1.000 & 1.000 & 0.031 & 0.062 & 0.062 & 0.500 \\
\hline Ampicillin & 0.062 & 0.031 & 0.095 & 0.095 & 0.007 & - \\
\hline Nystatin & - & & - & - & - & 0.007 \\
\hline
\end{tabular}

${ }^{a}$ The minimum fungicidal concentration MFC.

As shown in Tables 2 and 3, the MIC and MBC (MFC for C. albicans) values of 1,3,4-oxadiazole derivatives 1-7 are in concordance with the obtained inhibition zones, with MIC and MBC values ranging from 0.015 to $1.000 \mu \mathrm{g} \cdot \mathrm{mL}^{-1}$ and 0.031 to $1.000 \mu \mathrm{g} \cdot \mathrm{mL}^{-1}$, respectively.

The compounds 1-7 exhibited moderate MIC and MBC activity against Gram-negative strains (Tables 2 and 3). Regarding S. aureus and E. feacium, although the compounds 1-7 showed weaker MIC activity than that of Ampicillin, compounds 2, 3, 4, 5, and 7 exhibited relatively stronger MIC activity compared to that of compounds 1 and 6 . Interestingly, compounds $\mathbf{3}, \mathbf{4}$ and $\mathbf{7}$ showed MBC activity against $S$. aureus and E. feacium stronger or comparable to that of Ampicillin. In case of $S$. agalactiae, compounds 3, 4 and $\mathbf{7}$ exhibited relatively stronger MIC and MBC activity compared to others. It is noteworthy that only compound $\mathbf{4}$ exhibited stronger MIC and MBC activity than others though the MIC and MFC activities of $\mathbf{4}$ were weaker than that of Nystatin.

Importantly, the ratio MBC/MIC was close to 2, indicating that the synthesized 1,3,4oxadiazole derivatives were bactericidal in nature and not bacteriostatic [29].

This is illustrated in Table 4, by the exclusive correlation between MIC and MBC for the 1,3,4-oxadiazole derivatives, and on the other hand, by the absence of correlation of these two latter parameters with the inhibition zone diameter (IZD), index of bacteriostatic activity.

On the basis of obtained results from MIC and MBC values, compounds $\mathbf{3}$ and $\mathbf{4}$ bearing amidine moieties can be regarded as a new valuable source to produce new 1,3,4-oxadiazole derivatives against bacteria, especially Gram-positive as well as the fungus $C$. albicans. This indicates that the incorporation of significant functional unit such amidine, in symmetrical 2,5-positions, into the 1,3,4-oxadiazole 2,5-diamine $\mathbf{1}$, was as effective in obtaining of compounds $\mathbf{3}$ and $\mathbf{4}$ more active 
than the original precursor and which might be a potential source for synthetic products for the pharmaceutical industry against microorganisms of bacterial and fungal origin.

Table 4. Association between pMIC, pMBC and pIZD of 1,3,4-oxadiazole derivatives 1-7 against all bacterial and fungal strains tested.

\begin{tabular}{ccccccc}
\hline \multirow{2}{*}{ Compound } & \multicolumn{2}{c}{$\mathrm{pIZD}-\mathrm{pMIC}$} & \multicolumn{2}{c}{$\mathrm{pIZD}-\mathrm{pMBC}$} & \multicolumn{2}{c}{$\mathrm{pMIC}-\mathrm{pMBC}$} \\
\cline { 2 - 7 } & $\mathrm{r}$ & $p$-value & $\mathrm{r}$ & $p$-value & $\mathrm{r}$ & $p$-value \\
\hline $\mathbf{1}$ & $-0,7086$ & $\mathrm{NS}$ & $-0,5336$ & $\mathrm{NS}$ & 0,9120 & $<0,02$ \\
$\mathbf{2}$ & $-0,8503$ & $<0,05$ & $-0,8501$ & $<0,05$ & 1,0000 & $<0,0001$ \\
$\mathbf{3}$ & $-0,8347$ & $<0,05$ & $-0,8347$ & $<0,05$ & 1,0000 & $<0,0001$ \\
$\mathbf{4}$ & $-0,3193$ & $\mathrm{NS}$ & $-0,6253$ & $\mathrm{NS}$ & 0,8358 & $<0,05$ \\
$\mathbf{5}$ & $-0,2333$ & $\mathrm{NS}$ & $-0,0437$ & $\mathrm{NS}$ & 0,5124 & $\mathrm{NS}$ \\
$\mathbf{6}$ & 0,2151 & $\mathrm{NS}$ & $-0,3561$ & $\mathrm{NS}$ & 0,6252 & $\mathrm{NS}$ \\
$\mathbf{7}$ & $-0,9292$ & $<0,01$ & $-0,9290$ & $<0,01$ & 1,0000 & $<0,0001$ \\
\hline
\end{tabular}

${ }^{a}$ NS: Not Significant $\mathrm{pIZD}=-\log (\mathrm{IZD}) ; \mathrm{pMIC}=-\log (\mathrm{MIC})$ and $\mathrm{pMBC}=-\log (\mathrm{MBC}) ;$

Pearson's correlation coefficient $r$ was calculated to demonstrate intraspecific microbial association between pIZD, pMIC and pMBC. There was no correlation between pIZD and pMIC as well as between pIZD and pMBC for all bacterial and fungal strains tested.

In silico molecular docking. Among the molecular targets in pathogenic strains, enoyl-acyl carrier protein reductase (FabI) which catalyzes the last step of the type II fatty acid biosynthesis elongation cycle [30] has been validated as an attractive drug target [32]. This enzyme is indeed highly conserved across many clinically relevant pathogens, including E. coli and S. aureus, and represents the sole enoyl-ACP reductase present $[33,34]$.

In view of the promising antibacterial activity of 1,3,4-oxadiazole derivatives 3 and $\mathbf{4}$ against Gram-positive and Gram-negative selective FabI-containing organisms, and to get insight into the putative binding mode of these latter inhibitors in the active site of this enzyme, in silico molecular docking experiments were conducted as described previously [35,36], using the reported crystal structure of $S$. aureus FabI (saFabI) in complex with the inhibitor CG400549 and the cofactor NADPH in its active site (PDB entry code: 4CV1 [36]).

The best scoring position obtained (i.e. lowest energy complex) showed that compounds $\mathbf{3}$ and 4 may occupy the entire saFabI active site with predicted binding energy values $\Delta \mathrm{E}_{3}=-9.6 \mathrm{kcal} / \mathrm{mol}$ and $\Delta \mathrm{E}_{4}=-9.7 \mathrm{kcal} / \mathrm{mol}$, respectively. Moreover, a high level of concordance between the most favorable docked conformation of each compound and the crystalized CG400549 inhibitor (Fig. 2AB) was observed. Each of the docked compounds 3-saFabI and 4-saFabI complexes was then subjected to interactions analysis using Ligplot+ v.1.4 (Fig. 2C-D) [37]. The Ligplot+ diagram thus generated schematically depicts the hydrogen bonds and hydrophobic interactions between the ligand (i.e., 1,3,4-oxadiazole 3 or 4), the cofactor (i.e., NADPH) and the active site residues of the protein 
(i.e., saFabI) during the binding process. First, one 4-hydroxyphenylacetimidamide group from $\mathbf{3}$ and one 4-ethoxyphenylacetimidoyl group from 4 were found to bind deeply in the hydrophobic pocket where they interact with $\mathrm{Tyr}^{147}, \mathrm{Val}^{154}, \mathrm{Gln}^{155}, \mathrm{Tyr}^{157}, \mathrm{Ala}^{198}, \mathrm{Val}^{201}, \mathrm{Gly}^{203}, \mathrm{Phe}^{204}$ and $\mathrm{Ile}^{207}$. On the other side, the second amidine moiety of each compound may point towards the entrance of the active site thus interacting with $\mathrm{Phe}^{96}, \mathrm{Ala}^{97}, \mathrm{Met}^{160}$ and Leu ${ }^{196}$ residues. In addition, compound 4 would also be stabilized by seven H-bonding with $\mathrm{Ala}^{95}$ ( $2 \times \mathrm{H}$ bonds), $\mathrm{Tyr}^{147}$, and $\mathrm{Ser}^{197}$ residues, as well as with the NADPH nicotinamide ribose $2^{\prime}-\mathrm{OH}\left(2 \times \mathrm{H}\right.$ bonds) and the $\mathrm{NH}_{2}$ group of the 3carbamoylpyridinium (Fig. 2D). In contrast, only five H-bonding would be detected in the case of compound 3 involving Tyr $^{147}$ and Ser $^{197}$ residues, as well as the NADPH nicotinamide ribose 2'-OH ( $2 \times \mathrm{H}$ bonds) and the phosphate group of the adenine ribose (Fig. 2C). Taken together, these results would suggest that saFabI could be an effective target of our 1,3,4-oxadiazole derivatives 3 and $\mathbf{4}$. It is noteworthy that, in our in silico molecular model, Tyr $^{157}$, a key residue in saFabI activity, would only be involved in hydrophobic interactions (i.e., $\pi$-stacking interaction) with the aniline cycle of both compounds, contrary to inhibitors CG400549 and Triclosan for which a strong $\mathrm{H}$ bond was formed [36-38].

Although 1,3,4-oxadiazoles $\mathbf{3}$ and $\mathbf{4}$ may be able to inhibit FabI activity in either S. aureus or E. coli strains, the fact that compound $\mathbf{4}$ also impairs the growth of $C$. albicans which is lacking FabI enzyme, would suggest that in the latter bacteria this inhibitor might also interact with other enzyme(s) than FabI. 

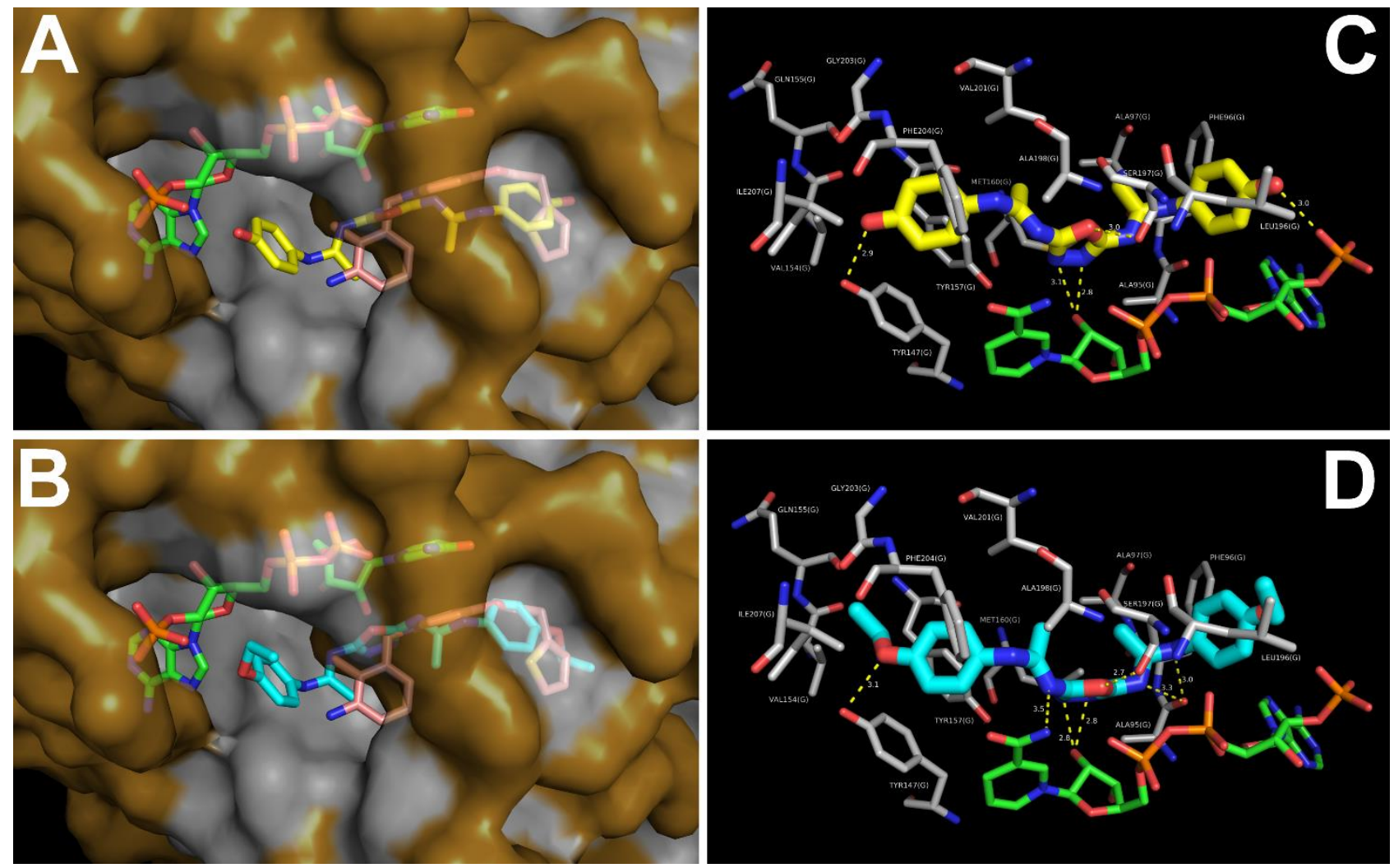

Figure 2. (A-B) in silico molecular docking of 1,3,4-oxadiazoles 3 (panel A - yellow color) and 4 (panel B - cyan color) into the crystallographic structures of $S$. aureus enoyl-acyl carrier protein reductase (saFabI) in a van der Waals surface representation, and superimposed to CG400549 (salmon color) saFabI inhibitor. NADPH cofactor also present in saFabI active site is colored in green. Hydrophobic residues (alanine, leucine, isoleucine, valine, tryptophan, tyrosine, phenylalanine, proline and methionine) are highlighted in white. (C-D) Ligplot+ analyses results: 3D representation of schematic binding mode of compounds $\mathbf{3}$ (panel $\mathbf{C}$ - yellow color) and $\mathbf{4}$ (panel $\mathbf{D}$ - cyan color) in complex with saFabI and NADPH (green color) showing both hydrogen-bonds (yellow dashed lines) and hydrophobic interactions. Selected residues of the saFabI binding pocket are shown as gray sticks. The stick representation uses the following atom colorcode: nitrogen, blue; oxygen, red; sulfur, yellow; phosphorus, orange. Structures were drawn with PyMOL Molecular Graphics System (Version 1.4, Schrödinger, LLC) using the PDB file 4CV1 [36]. 


\section{CONCLUSION}

In conclusion, we have successfully developed a straightforward one-step approach to 1,3,4oxadiazole-2,5-diamine, through the hydrogen peroxide-promoted oxidative dimerization of urea, followed by intramolecular cyclisation. A wide variety of unprecedented symmetrical 2,5difunctionalized 1,3,4-oxadiazoles bearing the amide, amidine, imine, or aminoguanidine functional groups, was then easily obtained from the reaction of 1,3,4-oxadiazole-2,5-diamine with different carbonyl or thiocarbonyl electrophiles such as salicylic acid, paracetamol, phenacetin, $\alpha$-tetralone, sorbic acid and thiosemicarbazide. All the synthesized compounds showed good to excellent antibacterial activities against several Gram positive and negative strains, and moderate antifungal activity against $C$. albicans. The compounds $\mathbf{3}$ and $\mathbf{4}$ bearing two amidine moieties in symmetrical 2,5-positions on the 1,3,4-oxadiazole ring, displayed the most potent antibacterial activities, in some cases better than Ampicillin control drug.

In silico molecular docking study have also brought useful and informative data regarding the potential binding mode of compounds 3 and $\mathbf{4}$ inside saFabI enzyme active site, therefore providing some clues for developing new lead compounds as potent antibacterial agents. Additionally, further investigation on the cytotoxicity of the obtained compounds against eukaryotic cells and diverse structural modifications are currently in progress through iterative synthesis in conjugation with computer modeling and the results will be reported in due course.

\section{EXPERIMENTAL}

Chemistry. Uncorrected melting points were determined on a Buchi apparatus. IR spectra ( $\mathrm{KBr}$ Discs) were performed on a 550 Nicolet Magana Spectrometer in the range $4000-400 \mathrm{~cm}^{-1} .{ }^{1} \mathrm{H}$ NMR $(500 \mathrm{MHz})$ and ${ }^{13} \mathrm{C}$ NMR (125 MHz) spectra were carried out on an MSL 500 Bruker spectrometer at room temperature. Chemical shifts $(\delta)$ were reported in parts per million (ppm), relative to tetramethylsilane (TMS) as internal reference. Elemental analyses for $\mathrm{C}, \mathrm{H}$, and $\mathrm{N}$ were performed on an instrument microanalyser Perkin Elmer CHNOS. All reagents and solvents were supplied by Aldrich chemical, with analytical grade, and were used as received without further purification. The chemical structures of compounds 1-7 were established based on their spectral data and they had shown purity greater than 95\%. NMR abbreviations and spin multiplicities are described as: $\mathrm{s}$ (singlet), d (doublet), $\mathrm{t}$ (triplet), q (quadruplet), m (multiplet), dd (doublet of doublet). Coupling constants $(J)$ are reported in Hertz $(\mathrm{Hz})$.

\section{Synthesis of 1,3,4-oxadiazole-2,5-diamine 1}

$6 \mathrm{~g}$ (100 mmol) of urea was introduced into a $50 \mathrm{~mL}$ round bottomed flask and $10 \mathrm{~mL}$ of $\mathrm{H}_{2} \mathrm{O}_{2}(40 \%)$ was added with $0.15 \mathrm{~mL}$ of concentrated $\mathrm{H}_{2} \mathrm{SO}_{4}(5 \mathrm{~mol} \%)$. The reaction mixture was then heated at 
reflux temperature with continuous stirring for 24 hours. After cooling to room temperature, the reaction mixture was left to crystallize for $24 \mathrm{~h}$. Crystals were then collected by filtration and recrystallized from absolute ethanol to afford a white solid. m. p.: $164{ }^{\circ} \mathrm{C}$. Yield: $(3.6 \mathrm{~g}) 72 \%$. IR $\left(\mathrm{KBr}, v\left(\mathrm{~cm}^{-1}\right)\right):$ 3387-3280 (N-H), $1570(\mathrm{C}=\mathrm{N}), 1232(\mathrm{C}-\mathrm{O}) .{ }^{1} \mathrm{H}$ NMR $\left(500 \mathrm{MHz}, \mathrm{DMSO}-\mathrm{d}_{6}\right) \delta=$ 7.95 (br, $\left.4 \mathrm{H}, 2 \mathrm{NH}_{2}\right) .{ }^{13} \mathrm{C}$ NMR (125MHz, DMSO-d 6 ) $\delta=160.59$. Anal. Calcd. for $\mathrm{C}_{2} \mathrm{H}_{4} \mathrm{~N}_{4} \mathrm{O}$. (100.08): C, 24; H, 4.03; N, 55.98; found: C, 24.03; H, 4.07; N, 56.01.

\section{General procedure for the synthesis of compounds 2-7}

A mixture of the carbonyl or thiocarbonyl electrophilic reagent (20 mmol, 2 equiv), 1,3,4-oxadiazole2,5-diamine (1) ( $1 \mathrm{~g}, 10 \mathrm{mmol}, 1$ equiv) and a catalytic amount of concentrated sulfuric acid $(0.1 \mathrm{~mL}$, $15 \mathrm{~mol} \%)$ in ethanol $(10 \mathrm{~mL})$ was stirred under reflux for 6 to $12 \mathrm{~h}$. After completion of the reaction as indicated by TLC, the reaction mixture was concentrated under reduced pressure. The residue was poured into water $(10 \mathrm{~mL})$ and extracted with chloroform $(3 \times 15 \mathrm{~mL})$. The combined organic layer was dried over anhydrous $\mathrm{MgSO}_{4}$, filtered and concentrated under vacuum to afford a solid, which was recrystallized from absolute ethanol.

\section{N,N'-(1,3,4-oxadiazole-2,5-diyl)bis(2-hydroxybenzamide) 2}

White solid. Yield: 86\%; m. p.: $167^{\circ} \mathrm{C}$. IR (KBr, $\left.v\left(\mathrm{~cm}^{-1}\right)\right): 3335(\mathrm{NH}), 3286(\mathrm{OH}), 1652(\mathrm{C}=\mathrm{O})$, $1600(\mathrm{C}=\mathrm{C}), 1562(\mathrm{C}=\mathrm{N}), 1252(\mathrm{C}-\mathrm{O}) .{ }^{1} \mathrm{H}$ NMR $\left(\mathrm{DMSO}_{\mathrm{d}}\right) \delta=10.43(\mathrm{br}, 4 \mathrm{H}, 2 \mathrm{OH}, 2 \mathrm{NH}), 7.70(\mathrm{~d}$, $2 \mathrm{H}, J=6.5), 7.30(\mathrm{~d}, 2 \mathrm{H}, J=7.5), 6.80(\mathrm{dd}, 4 \mathrm{H}, J=7.5) .{ }^{13} \mathrm{C}$ NMR $(125 \mathrm{MHz}$, DMSO-d 6$) \delta=164.62$, 162.38; 161.73, 135.78, 130.31, 119.31, 117.36, 113.26. Anal. Calcd. for $\mathrm{C}_{16} \mathrm{H}_{12} \mathrm{~N}_{4} \mathrm{O}_{5}$ (340.29): C, 56.47; H, 3.55; N, 16.46; O, 23.51; found: C, 56.51; H, 3.60; N, 16.48.

\section{$N, N^{\prime}$-(1,3,4-oxadiazole-2,5-diyl) bis(N-(4-hydroxyphenyl)acetimidamide) 3}

White solid. Yield: 80\%. m. p.: $128^{\circ} \mathrm{C}$. IR (KBr, $\left.v\left(\mathrm{~cm}^{-1}\right)\right): 3452(\mathrm{OH}), 3340(\mathrm{NH}), 1659(\mathrm{C}=\mathrm{N})$, $1570(\mathrm{C}=\mathrm{N}), 1600(\mathrm{C}=\mathrm{C}) .{ }^{1} \mathrm{H}$ NMR (DMSO-d $) \delta=9.76(\mathrm{br}, 2 \mathrm{H}, 2 \mathrm{OH}), 9.41(\mathrm{br}, 2 \mathrm{H}, 2 \mathrm{NH}), 7.39(\mathrm{~d}$, $4 \mathrm{H}, J=9), 6.75(\mathrm{~d}, 4 \mathrm{H}, J=8.5), 2.03\left(\mathrm{~s}, 6 \mathrm{H}, 2 \mathrm{CH}_{3}\right) .{ }^{13} \mathrm{C}$ NMR $\left(125 \mathrm{MHz}, \mathrm{DMSO}-\mathrm{d}_{6}\right) \delta=161.13,160.68$, 153.76, 131.23, 121.77, 115.57, 24. Anal. Calcd. for $\mathrm{C}_{18} \mathrm{H}_{18} \mathrm{~N}_{6} \mathrm{O}_{3}$ (366.37): C, 59.01; H, 4.95; N, 22.94; found: C, 58.95; H, 5; N, 22.98.

\section{N, N'-(4-ethoxyphenyl)bis(acetimidoyl) amino-1,3,4-oxadiazol-2-yl-acetamide 4}

Brown solid. Yield: 79\%. m. p.: $140{ }^{\circ} \mathrm{C}$. IR (KBr, $\left.v\left(\mathrm{~cm}^{-1}\right)\right): 3297(\mathrm{NH}), 1660(\mathrm{C}=\mathrm{N}), 1560(\mathrm{C}=\mathrm{N})$. ${ }^{1} \mathrm{H}$ NMR (DMSO-d 6 ) $\delta=9.80$ (br, 2H, 2NH), 7.51 (d, 4H, J=9), 6.80 (d, 4H, J=9.5), 3.95 (q, 4H, 2 $\left.\mathrm{OCH}_{2}, J=7\right), 2.04$ (s, 6H, 2CH 3$), 1.30\left(\mathrm{t}, 6 \mathrm{H}, 2 \mathrm{CH}_{3}, J=7\right) .{ }^{13} \mathrm{C}$ NMR $\left(125 \mathrm{MHz}, \mathrm{DMSO}-\mathrm{d}_{6}\right) \delta=161.28$, 160.44, 154.80, 132.87, 121.05, 114.69, 63.48, 24.19, 15.09. Anal. Calcd. for $\mathrm{C}_{22} \mathrm{H}_{26} \mathrm{~N}_{6} \mathrm{O}_{3}(422.48)$ : C, 62.54; H, 6.20; N, 19.89; found: C, 62.51; H, 6.23; N, 19.94 . 
N,N'-(1,3,4-oxadiazole-2,5-diyl)bis(3,4-dihydronaphthalen-1(2H)-imine) 5

Brown solid. Yield: 76\%. m. p.: 242 ${ }^{\circ}$ C. IR (KBr, $\left.v\left(\mathrm{~cm}^{-1}\right)\right): 1645(\mathrm{C}=\mathrm{N}), 1557(\mathrm{C}=\mathrm{N}), 1613(\mathrm{C}=\mathrm{C})$. ${ }^{1} \mathrm{H}$ NMR (DMSO-d $) \delta=8.45$ (d, 2H, $\left.J=9,5\right), 8.08$ (dd, 2H, $J=9$ ), 7.59 (dd, 2H, J=9), 7.47 (d, 2H, $J=9,5), 2.93(\mathrm{t}, 4 \mathrm{H}, J=7), 2.53(\mathrm{t}, 4 \mathrm{H}, J=7), 2.07(\mathrm{~m}, 4 \mathrm{H}) .{ }^{13} \mathrm{C}$ NMR $(125 \mathrm{MHz}$, DMSO-d 6$) \delta=160.13$, 151.40, 144.63, 135.74, 132.21, 128.37, 126.21, 122.19, 23.98, 27.26, 28.05. Anal. Calcd. for $\mathrm{C}_{22} \mathrm{H}_{20} \mathrm{~N}_{4} \mathrm{O}$ (356.16): C, 74.14; H, 5.66; N, 15.72; found: C, 74.18; H, 5.63; N, 15.75.

\section{1,1'-(1,3,4-oxadiazole-2,5-diyl)bis(6-methyl-5,6-dihydropyridin-2(1H)-one) 6}

Yellow solid. Yield: 75\%; m. p.: 124 C. IR (KBr, $\left.v\left(\mathrm{~cm}^{-1}\right)\right)$ : $1665(\mathrm{C}=\mathrm{O}), 1603(\mathrm{C}=\mathrm{C}), 1563(\mathrm{C}=\mathrm{N})$. ${ }^{1} \mathrm{H}$ NMR (DMSO-d 6$) \delta=7.51(\mathrm{~d}, 2 \mathrm{H} ; J=10,5), 6.85(\mathrm{~m}, 2 \mathrm{H}), 3.94(\mathrm{~m}, 2 \mathrm{H}), 2.55(\mathrm{~m}, 2 \mathrm{H}), 2.04(\mathrm{~m}$, $2 \mathrm{H}), 1.31\left(\mathrm{~d}, 6 \mathrm{H}, 2 \mathrm{CH}_{3}, J=7,5\right) .{ }^{13} \mathrm{C} \mathrm{NMR}\left(125 \mathrm{MHz}, \mathrm{DMSO}-\mathrm{d}_{6}\right) \delta=165.28,162.44,132.8,123.05$, 67.48, 33.50, 20.95. Anal. Calcd. for $\mathrm{C}_{14} \mathrm{H}_{16} \mathrm{~N}_{4} \mathrm{O}_{3}$ (288.12): C, 58.32; H, 5.59; N, 19.43; found: C,58.27; H, 5.62; N, 19.47.

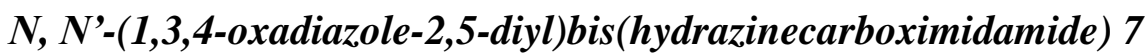

Yellow solid. Yield: 84\%; m. p.: $262^{\circ} \mathrm{C}$. IR $\left(\mathrm{KBr}, v\left(\mathrm{~cm}^{-1}\right)\right): 3344\left(\mathrm{NH}_{2}\right), 3236(\mathrm{NH}), 1654(\mathrm{C}=\mathrm{N})$, $1558(\mathrm{C}=\mathrm{N}) .{ }^{1} \mathrm{H}$ NMR (DMSO-d 6$) \delta=8.40\left(\mathrm{br}, 4 \mathrm{H}, 2 \mathrm{NH}_{2}\right), 6.00(\mathrm{br}, 2 \mathrm{H}, 2 \mathrm{NH}), 4.80\left(\mathrm{br}, 4 \mathrm{H}, 2 \mathrm{NH}_{2}\right)$. ${ }^{13} \mathrm{C}$ NMR (125MHz, DMSO-d 6 ) $\delta=161.90,158.90$. Anal. Calcd. for $\mathrm{C}_{4} \mathrm{H}_{10} \mathrm{~N}_{10} \mathrm{O}$ (214.10): C, 22.43; H, 4.71; N, 65.39; found: C, 22.48; H, 4.74; N, 65,38.

Antimicrobial evaluation. The used microorganisms; Gram(-): Escherichia coli (ATCC 8739), Salmonella typhimurium (ATCC 14028), Gram(+): Staphylococcus aureus (ATCC 6538), Enterococcus feacium (ATCC 19434), Streptococcus B (agalactiae), and the fungus Candida albicans (ATCC 10231); were from Microbiology Laboratory of National Institute INRAP Biotech Pole - Sidi Thabet, Tunis, Tunisia. Prior to use, the bacteria and fungus are subcultured and incubated under optimal growth conditions. They are conserved by transplanting on nutrient agar favorable for their growth for $24 \mathrm{~h}$, in the dark and at $37^{\circ} \mathrm{C}$. Nutrient agar was used to culture the microbes. The plates were inculcated by the microbes and incubated for $24 \mathrm{~h}$ at $37{ }^{\circ} \mathrm{C}$. Ampicillin and Nystatin, at a concentration of $10 \mu \mathrm{g} \cdot \mathrm{mL}^{-1}$ and $100 \mu \mathrm{g} \cdot \mathrm{mL}^{-1}$ respectively and were used as reference drugs against microbes. All the microbes were grown on Mueller-Hinton Agar (Hi-media) plates $\left(37^{\circ} \mathrm{C}, 24 \mathrm{~h}\right)$.

Inhibition-zone measurement. A suspension of the tested microorganisms was spread on the appropriate solid media plates and incubated overnight at $37^{\circ} \mathrm{C}$. After 1 day, 4-5 loops of pure colonies were transferred to saline solution in a test tube for each bacterial strain and adjusted to the $0.5 \mathrm{McFarland}$ turbidity standard $\left(\sim 10^{8}\right.$ cells. $\left.\mathrm{mL}^{-1}\right)$. Sterile cotton dipped into the bacterial suspension and the agar plates were streaked three times, each time turning the plate at a $60^{\circ}$ angle and finally rubbing the swab through the edge of the plate. Sterile paper discs (Glass Microfibre filters, Whatman; 
$6 \mathrm{~mm}$ in diameter) were placed onto inoculated plates and impregnated with the diluted solutions in sterile water. Ampicillin ( $15 \mu \mathrm{g} / \mathrm{disc})$ was used as positive control for all strains except $C$. albicans for which nystatin $\left(100 \mu \mathrm{g} /\right.$ disc) was used. Inoculated plates with discs were placed in a $37{ }^{\circ} \mathrm{C}$ incubator. After $24 \mathrm{~h}$ of incubation, the results were recorded by measuring the zones of growth inhibition surrounding the filter paper disc in millimeters. Clear inhibition zones around the discs indicated the presence of antimicrobial activity. The test was run in duplicate.

Minimum inhibitory concentration (MIC) measurement. The MIC was considered to be the lowest concentration that completely inhibited the growth on agar plates, disregarding a single colony or faint haze caused by the inoculum. The MIC values were determined in 96 well-microplate using the microdilution method according to reference [29]. Briefly, a stock solution of each product was prepared in DMSO. Then, serial dilutions of all tested products were performed in Mueller Hinton Broth medium (MHB) to obtain final concentrations in the range of $10 \mu \mathrm{g} / \mathrm{mL}$ to $0.0025 \mu \mathrm{g} / \mathrm{mL}$. The 12th well was considered as growth control (free drug control). Afterwards, $50 \mu \mathrm{L}$ of bacterial inoculum was added to each well at a final concentration of $10^{6} \mathrm{CFU} / \mathrm{mL}$. After incubation at $37{ }^{\circ} \mathrm{C}$ for $24 \mathrm{~h}, 10 \mu \mathrm{L}$ of MTT were added to each well as bacterial growth indicator. After further incubation at $37^{\circ} \mathrm{C}$ for $2 \mathrm{~h}$, the bacterial growth was revealed by the change of coloration from yellow to black. The MIC was considered to be the lowest active compound concentration at which growth inhibition was clearly visible (absence of the color change at the bottom of the well) within a defined period of time.

Minimal bactericidal concentration (MBC) measurement. MIC tests were always extended to measure the MBC as follows: a loop-full from the tube that did not show visible growth (MIC) was spread over a quarter of Müller-Hinton agar plate. After $18 \mathrm{~h}$ of incubation at $37^{\circ} \mathrm{C}$, the plates were examined for CFU count. Again, the tube containing the lowest concentration of the test compound that failed to yield growth on subculture plates was considered the MBC for the respective test organism (Table 3). Thus, it reduces by $99.9 \%$ the in vitro survival of micro-organisms in a medium containing a defined inoculum of bacteria, within a defined period of time.

Statistical analysis. Results of quantitative variables were expressed as the arithmetic mean. Statistical analysis of the data was performed using MS Excel for descriptive statistics and Pearson's correlation between parameters. All values were considered significant at $\mathrm{P}<0.05$.

Molecular docking experiments. A computational docking and scoring procedure using the Autodock Vina program [39] was used to generate the putative binding modes of 1,3,4-oxadiazoles 3 and 4 into the active site of the S. aureus enoyl-acyl carrier protein reductase (saFabI) as previously described [35]. The PyMOL Molecular Graphics System (version 1.4, Schrödinger, LLC) was used as working environment with an in-house version of the AutoDock/Vina PyMOL plugin [40]. The 
X-ray crystallographic structure of saFabI in complex with the inhibitor CG400549 and the cofactor NADPH in its active site (PDB entry code: 4CV1; $1.95 \AA$ resolution [36]) available at the Protein Data Bank was used as receptor. Docking runs were performed after removing the ligand (i.e., CG400549 inhibitor) from the enzyme active site. The box size used for the receptor was chosen to fit the whole active site cleft and to allow non constructive binding positions. The binding site region was defined by NADPH and amino acids 93-99, 102, 121, 146-147, 154-157, 160, 164, 190-193, 195, 197-204, and 207 as previously reported [36]. A model structure file was generated for the inhibitor molecules, and their geometry was refined using the Avogadro open-source program (version 1.1.1. http://avogadro.openmolecules.net/).

As a first step, compound CG400549 was submitted to in silico molecular docking into saFabI active site. Comparison of the generated CG400549 docking pose with the available binding geometry observed in the $4 \mathrm{CV} 1$ crystal structure revealed root mean square deviations of $0.230 \AA$ for the top ranked pose (predicted binding energy value, $\Delta \mathrm{ECG}_{\mathbf{4} 40549}=-10.3 \mathrm{kcal} / \mathrm{mol}$ ). This re-/cross-docking experiment thus confirms the validity and reliability of our computational approach.

\section{REFERENCES AND NOTES}

[1] D.L. Mayers, S.A. Lerner, M. Ouelette, Antimicrobial Drug Resistance C: Clinical and Epidemiological Aspects, vol.2, Springer Dordrecht Heidelberg, London, 2009.

[2] Guschin, P. Ryzhikh, T. Rumyantseva, M. Gomberg, M. Unemo, BMC Infect. Dis. 2015, 15, 1.

[3] Martin, P. Sawatzky, G. Liu, M.R. Mulvey, Can. Commun. Dis. Rep. 2015, 41, 35.

[4] G. A. Durand, D. Raoult, G. Dubourg, Int J Antimicrob Agents 2019, 53, 371.

[5] Z. Zheng, Q. Liu, W. Kim, N. Tharmalingam, B.B. Fuchs, E. Mylonakis, Future Med. Chem. 2018, 10, 283.

[6] F. Karimi, A. Souldozi, N.H. Jazani, J. Chem. Pharm. Res. 2015, 7, 1028.

[7] H. Khalilullah, S. Khan, M.S. Nomani, B. Ahmed, Arab. J. Chem. 2016, S1029-1035.

[8] P.Y. Wang, W.B. Shao, H.T. Xue, H.S. Fang, J. Zhou, Z.B. Wu, B.A. Song, S. Yang, Research Chem. Inter. 2017, 48, 6115.

[9] P. Li, L. Shi, X. Yang, L. Yang, X.W. Chen, F. Wu, Q.C. Shi, W.M. Xu, M. He, D.Y. Hu, B.A. Song, Bioorg. Med. Chem. Lett. 2014, 24, 1677.

[10] M.Y. Wani, A. Ahmed, R. A. Shiekh, K. J. Al-Gamdi, A.J. Sobral, Bioorg. Med. Chem. 2015, 23,4172 .

[11] C.I. Stoica, I. Ionut, L. Vlase, B. Tiperciuc, G. Marc, S. Oniga, C. Araniciu, O. Oniga, Biomed. Chromatogr, 2018, 32, e4221.

[12] F. Yu, A. Guan, M. Li, L. Hu, X. Li, Chinese. Chem. Lett. 2018, 29, 915. 
[13] Z. Li, P. Zhan, X. Liu, Mini Rev. Med. Chem. 2011, 11, 1130.

[14] W. Wu, Q. Chen, A. Tai, G. Jiang, G. Ouyang, Bioorg. Med. Chem. Lett. 2015, 25, 2243.

[15] A. Almasirad, Z. Mousavi, M. Tajik, M. J. Assarzadeh, A. Shafiee, DARU-J. Pharm. Sci. 2014, $22,22$.

[16] P. Pitasse-Santos, V. Sueth-Santiago, E.F.L. Marco, J. Braz. Chem. Soc. 2018, 29, 435.

[17] W.A. El-Sayed, F.A. El-Essawy, O.M. Ali, B.S. Nasr, M.M. Abdalla, A.A. Abdel-Rahman, Z. Naturforsch C. 2009, 64, 773.

[18] M.H. Khan, T. Akhtar, N.A. Al-Masoudi, H. Stoeckli-Evans, S. Hameed, Med. Chem. 2012, 8, 190.

[19] L. Yurttas, E.F. Bulbul, S. Tekinkoca, S. Demirayak, Acta Pharm. Sci. 2017, 55, 45.

[20] K.L. Leach, S.J. Brickner, M.C. Noe, P.F. Miller, Ann. N Y Acad. Sci. 2011, 1222.

[21] J. Cohen, W.G. Powderly, S.M. Opal, Infectious Diseases, Elsevier Health Sciences 2016.

[22] M. Kratky, M. Dzurkova, J. Janousek, K. Konecna, F. Trejtnar, J. Stolarikova, J. Vinsova, Molecules 2017, 22, 1573.

[23] M. Song, S. Wang, Z. Wang, Z. Fu, S. Zhou, H. Cheng, Z. Liang, X. Deng, Eur. J. Med. Chem. 2019, 166, 108.

[24] (a) M. Hermi, W. Kaminsky, C. Ben Nasr, S. Touil, Org. Prep. Proced. Int. 2018, 50, 432. (b)

I. Essid, S. Touil, Arkivoc 2013, 98. (c) E. Chebil, M. Chamakhi, S. Touil, J. Sulfur Chem. 2011, 32 , 249. (d) A. Samarat, J. Ben Kraïem, T. Ben Ayed, H. Amri, Tetrahedron 2008, 64, 9540. (e) A. Samarat, H. Amri, Y. Landais, Tetrahedron 2004, 60, 8949.

[25] M. Qi, R. Guo, M. Su, X. Cheng, L. Zhang, App. Mech. Mat. 2014, 448-453,464.

[26] M. Brahmaya, F.S. Liu, S.Y. Suen, C.C. Huang, S.A. Dai, Y.S. Guo, Y.F. Chen, Res. Chem. Intermed. 2016, 42, 1965.

[27] J. E. Baldwin, J. A. Reiss, J. Chem. Soc. Chem. Commun. 1977, 3, 77.

[28] R.R. Hafidh, A.S. Abdulamir, L.S. Vern, F.A. Bakar, F. Abas, F. Jahanshiri, Z. Sekawi, Open Microbiol. J. 2011, 5, 96.

[29] European Committee for Antimicrobial Susceptibility Testing (EUCAST) of the European Society of Clinical Microbiology and Infectious Diseases (ESCMID). Clin. Microbiol. Infect. 2000, $6,509$.

[30] (a) W.P. Kennedy, A.T. Wallace, J. M. Murdoch, Br. Med. J. 1963, 2, 962. (b) R. Sutherland, G.N. Rolinson, J. Clin. Path. 1964, 17, 461. 
[31] X. Zhang, T. Li, X. Chen, S. Wang, Z. Liu, BMC Microbiol. 2018, 18, 166.

[32] H. Xu, T.J. Sullivan, J. Sekiguchi, T. Kirikae, I. Ojima, C.F. Stratton, W. Mao, F.L. Rock, M.R. Alley, F. Johnson, S.G. Walker, P.J. Tonge, Biochemistry 2008, 47, 4228.

[33] (a) V. Gerusz. Recent advances in the inhibition of bacterial fatty acid biosynthesis, Annual Reports in Medicinal Chemistry, Academic Press, New York 2010. (b) V. Gerusz, A. Denis, F. Faivre, Y. Bonvin, M. Oxoby, S. Briet, G. LeFralliec, C. Oliveira, N. Desroy, C. Raymond, L. Peltier, F. Moreau, S. Escaich, V. Vongsouthi, S. Floquet, E. Drocourt, A. Walton, L. Prouvensier, M. Saccomani, L. Durant, J. M. Genevard, V. Sam-Sambo, C. Soulama-Mouze, J. Med. Chem. 2012, 55, 9914. (c) H. Lu, P.J. Tonge, Acc. Chem. Res. 2008, 41, 11.

[34] D.J. Payne, M.N. Gwynn, D.J. Holmes, D.L. Pompliano, Nat. Rev. Drug. Discov. 2007, 6, 29.

[35] (a) V. Point, R.K. Malla, S. Diomande, B.P. Martin, V. Delorme, F. Carriere, S. Canaan, N.P. Rath, C.D. Spilling, J.-F. Cavalier J. Med. Chem. 2012, 55, 10204. (b) V. Point, A. Bénarouche, J. Zarillo, A. Guy, R. Magnez, L. Fonseca, B. Raux, J. Leclaire, G. Buono, F. Fotiadu, T. Durand, F. Carrière, C. Vaysse, L. Couëdelo, J.-F. Cavalier, Eur. J. Med. Chem. 2016, 123, 834. (c) P.C. Nguyen, V. Delorme, A. Bénarouche, B.P. Martin, R. Paudel, G.R. Gnawali, A. Madani, R. Puppo, V. Landry, L. Kremer, P. Brodin, C.D. Spilling, J.-F. Cavalier, S. Canaan, Scientific Reports 2017, 7, 11751.

[36] J. Schiebel, A. Chang, S. Shah, Y. Lu, L. Liu, P. Pan, M.W. Hirschbeck, M. Tareilus, S. Eltschkner, W. Yu, J.E. Cummings, S.E. Knudson, G.R. Bommineni, S.G. Walker, R.A. Slayden, C.A. Sotriffer, P.J. Tonge, C. Kisker, J. Biol. Chem. 2014, 289, 15987.

[37] R.A. Laskowski, M.B. Swindells, J. Chem. Inf. Model. 2011, 51, 2778.

[38] J. Schiebel, A. Chang, H. Lu, M.V. Baxter, P.J. Tonge, C. Kisker, Structure 2012, $20,802$.

[39] O. Trott, A. J. Olson, J. Comput. Chem. 2010, 31, 455.

[40] D. Seeliger, B. L. de Groot, J. Comput. Aided Mol. Des. 2010, 24, 417. 
Table 1. The in vitro antimicrobial activity of compounds 1-7 and the control drugs.

\begin{tabular}{ccccccc}
\hline \multirow{2}{*}{ Compound $^{\mathrm{a}}$} & \multicolumn{7}{c}{ Inhibition zone diameter $(\mathrm{mm})$} \\
\cline { 2 - 7 } & E. coli & S. typhimurium & S. aureus & E. feacium & S. agalactiae & C. albicans \\
\hline $\mathbf{1}$ & 7.00 & 7.50 & 7.00 & 9.00 & 8.50 & 8.00 \\
$\mathbf{2}$ & 9.25 & 9.50 & 15.25 & 25.50 & 37.75 & 9.25 \\
$\mathbf{3}$ & 13.75 & 12.00 & 18.25 & 27.00 & 36.50 & 11.00 \\
$\mathbf{4}$ & 12.75 & 11.50 & 16.00 & 25.50 & 46.50 & 11.25 \\
$\mathbf{5}$ & 12.25 & 12.25 & 14.25 & 17.75 & 29.25 & 10.00 \\
$\mathbf{6}$ & 10.00 & 9.50 & 13.25 & 15.00 & 15.50 & 10.50 \\
$\mathbf{7}$ & 10.50 & 10.00 & 17.75 & 25.00 & 36.50 & 11.00 \\
Ampicillin $^{\mathrm{a}}$ & 12 & 14.50 & 34.75 & 37.00 & 28.75 & - \\
Nystatin $^{\mathrm{b}}$ & - & & - & - & - & 30.75 \\
\hline
\end{tabular}

${ }^{a}$ At the concentration of $15 \mu \mathrm{g} / \mathrm{mL},{ }^{b}$ At the concentration of $100 \mu \mathrm{g} / \mathrm{mL}$.

Table 2. Minimum inhibitory concentration (MIC) of compounds 1-7

\begin{tabular}{ccccccc}
\hline \multirow{2}{*}{ Compound } & \multicolumn{7}{c}{ MIC $\left(\mu \mathrm{\mu g} \mathrm{mL}^{-1}\right)$} \\
\cline { 2 - 6 } & E. coli & S. typhimurium & S. aureus & E. feacium & S. agalactiae & C. albicans \\
\hline $\mathbf{1}$ & 1.000 & 0.500 & 1.000 & 0.500 & 0.250 & 0.250 \\
$\mathbf{3}$ & 0.500 & 0.500 & 0.062 & 0.062 & 0.062 & 0.250 \\
$\mathbf{4}$ & 0.500 & 0.500 & 0.031 & 0.031 & 0.031 & 0.500 \\
$\mathbf{5}$ & 0.500 & 0.500 & 0.015 & 0.015 & 0.015 & 0.015 \\
$\mathbf{6}$ & 0.500 & 0.500 & 0.062 & 0.125 & 0.250 & 0.250 \\
$\mathbf{7}$ & 0.500 & 0.500 & 1.000 & 0.500 & 0.500 & 0.500 \\
Ampicillin & 0.500 & 0.500 & 0.015 & 0.031 & 0.031 & 0.250 \\
Nystatin & 0.031 & 0.015 & 0.004 & 0.004 & 0.003 & - \\
\hline
\end{tabular}

Table 3. Minimum bactericidal concentration (MBC) of compounds 1-7

\begin{tabular}{|c|c|c|c|c|c|c|}
\hline \multirow{2}{*}{ Compound } & \multicolumn{6}{|c|}{$\mathrm{MBC}(\mu \mathrm{g} / \mathrm{mL})$} \\
\hline & E. coli & S. typhimurium & S. aureus & E. feacium & S. agalactiae & C. albicans $^{a}$ \\
\hline 1 & 1.000 & 1.000 & 1.500 & 1.000 & 0.500 & 0.500 \\
\hline 2 & 1.000 & 1.000 & 0.125 & 0.125 & 0.125 & 0.500 \\
\hline 3 & 1.000 & 1.000 & 0.062 & 0.062 & 0.062 & 1.000 \\
\hline 4 & 0.500 & 0.500 & 0.031 & 0.031 & 0.031 & 0.031 \\
\hline 5 & 1.000 & 1.000 & 0.125 & 0.250 & 0.125 & 1.000 \\
\hline 6 & 1.000 & 1.000 & 1.500 & 1.000 & 0.500 & 1.000 \\
\hline 7 & 1.000 & 1.000 & 0.031 & 0.062 & 0.062 & 0.500 \\
\hline Ampicillin & 0.062 & 0.031 & 0.095 & 0.095 & 0.007 & - \\
\hline Nystatin & - & & - & - & - & 0.007 \\
\hline
\end{tabular}

$a$ The minimum fungicidal concentration MFC. 
Table 4. Association between pMIC, pMBC and pIZD of 1,3,4-oxadiazole derivatives 1-7 against all bacterial and fungal strains tested.

\begin{tabular}{ccccccc}
\hline \multirow{2}{*}{ Compound } & \multicolumn{2}{c}{$\mathrm{pIZD}-\mathrm{pMIC}$} & \multicolumn{2}{c}{$\mathrm{pIZD}-\mathrm{pMBC}$} & \multicolumn{2}{c}{$\mathrm{pMIC}$ - pMBC } \\
\cline { 2 - 6 } & $\mathrm{r}$ & $p$-value & $\mathrm{r}$ & $p$-value & $\mathrm{r}$ & $p$-value \\
\hline $\mathbf{1}$ & $-0,7086$ & $\mathrm{NS}$ & $-0,5336$ & $\mathrm{NS}$ & 0,9120 & $<0,02$ \\
$\mathbf{2}$ & $-0,8503$ & $<0,05$ & $-0,8501$ & $<0,05$ & 1,0000 & $<0,0001$ \\
$\mathbf{3}$ & $-0,8347$ & $<0,05$ & $-0,8347$ & $<0,05$ & 1,0000 & $<0,0001$ \\
$\mathbf{4}$ & $-0,3193$ & $\mathrm{NS}$ & $-0,6253$ & $\mathrm{NS}$ & 0,8358 & $<0,05$ \\
$\mathbf{5}$ & $-0,2333$ & $\mathrm{NS}$ & $-0,0437$ & $\mathrm{NS}$ & 0,5124 & $\mathrm{NS}$ \\
$\mathbf{6}$ & 0,2151 & $\mathrm{NS}$ & $-0,3561$ & $\mathrm{NS}$ & 0,6252 & $\mathrm{NS}$ \\
$\mathbf{7}$ & $-0,9292$ & $<0,01$ & $-0,9290$ & $<0,01$ & 1,0000 & $<0,0001$ \\
\hline
\end{tabular}

${ }^{a}$ NS: Not Significant

$\mathrm{pIZD}=-\log (\mathrm{IZD}) ; \mathrm{pMIC}=-\log (\mathrm{MIC})$ and $\mathrm{pMBC}=-\log (\mathrm{MBC}) ;$

Pearson's correlation coefficient $r$ was calculated to demonstrate intraspecific microbial association between pIZD, pMIC and pMBC. There was no correlation between pIZD and pMIC as well as between pIZD and pMBC for all bacterial and fungal strains tested. 